\title{
YOUR PROFESSION, YOUR EVENT
}

Dental care professionals (DCPs) can look forward to another entertaining and educational British Dental Conference and Exhibition on 26-28 April 2012. Although the event may be returning to the same venue as in 2011, the stunning Manchester Central Convention Complex, it promises to be fresh, inspirational and vital.

Well-established as one of the most important dates in the dental calendar, the event provides the opportunity to see a variety of demonstrations in a dedicated DCP theatre, check out the latest product innovations and attend a wide range of relevant training sessions. Attendees will also enjoy a full programme of seminars helping them meet their CPD requirements. As always, there will be a strong presence from the DCP representative organisations, with many of them confirmed to both exhibit and host sessions at the event. It will also feature the usual dynamic programme of entertainment, giving you a chance to let your hair down and catch up with peers. Over 4,500 people attended the 2011 event and there is even more on offer for 2012.

One new feature is the live demonstration theatre in the exhibition hall. It will provide space for up to 70 delegates seated around an open stage. For the full three days, a varied programme of hands-on and watch-andlearn sessions will be presented by a range of experts offering free verifiable CPD. Sessions will emphasise the practical approach with the use of phantom head simulators and role play enactments.

Topics that will be covered include managing dental anxiety; integrating dental photography into everyday practice and medical emergencies.
The Training essentials theatre, also in the exhibition hall, will offer an extensive programme of free 30 minute bite-sized lectures, all designed to meet the training needs of the whole dental team. The lectures will provide verifiable $\mathrm{CPD}$ and will cover a range of topics including: regulatory updates; business management; and personal development.

The main conference programme will also have plenty to interest DCPs; sessions already scheduled include: Why the team approach makes sense for delivering effective teeth whitening; Maintaining healthy implants: the key to success; Communications in practice; Prevention is better than cure; Infection control; and Radiography.

The extensive exhibition provides an opportunity for everyone to test drive and discuss new products, as well as meeting those behind the innovations. There will be product launches, giveaways, a D-Stress \& Go relaxation zone, an internet café and much more.

2012's social programme includes a Friday night party at The Palace Hotel featuring Europe's top Queen tribute band 'Killer Queen. On Saturday, a black-tie conference dinner with entertainment at the Hilton Deansgate Hotel provides an excuse for the team to don dinner jackets and posh frocks.

Registration for the event opened on 14 November 2011 with a discounted early bird rate available for a limited period.

To register visit www.bda.org/conference or call 0870166 6625. A free DCP conference ticket is on offer with every dentist conference booking, so team up with colleagues to ensure everyone benefits (exclusions apply). of The Year 2011 title. They will be listed on the historic BDA Annual Honours and Awards roll.

Natalie Francis was presented with the University of Portsmouth Dental Academy Dental Nursing Practice Award at the CertHE in Dental Nursing Graduation Ceremony.

The dental team at St Helen's Dental Practice in Cockermouth, Cumbria, have won the Investors in People Gold standard. This puts the practice in the top $1.5 \%$ of over 21,000 UK businesses that have achieved the Investors in People Standard and the only dental practice in the North West to achieve the GOLD award. , 